\title{
Erro Médico
}

José Augusto Simões*

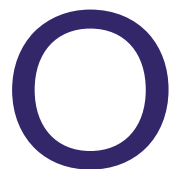

Erro Médico é a falha do médico no exercício da sua profissão. É portanto, um mau resultado ou evento adverso decorrente da sua acção ou omissão, por inobservância de procedimento técnico, estando o médico no pleno exercício das suas faculdades mentais. Excluem-se as limitações impostas pela própria natureza da doença, bem como as lesões produzidas deliberadamente para tratar um mal maior. ${ }^{1}$

O Erro Médico pode ocorrer por:

a) Imperícia, decorrente da falta de observação das normas técnicas, por falta de preparação ou por insuficiência de conhecimentos. Por exemplo quando o médico realiza procedimentos para os quais não está habilitado;

b) Imprudência, quando o médico assume riscos no tratamento do paciente sem substrato científico para o seu procedimento;

c) Negligência, quando são violadas as regras de segurança ou quando o médico falta à sua obrigação de tratar, podendo fazê-lo. ${ }^{2}$

No entanto, actualmente, qualquer insatisfação dos pacientes quanto a tratamentos médicos tende a ser descrita por esses como «erro médico». Mas, o erro de um médico precisa, necessariamente, de ser enquadrado em alguma das características supracitadas para ser assim classificado.

Outros problemas podem ser classificados como erro médico, tais como:

- A falha técnica, que depende da competência e da dedicação do médico, mas também da resposta do paciente, da doença ou de uma intercorrência.

- O erro doloso, que é o cometido voluntariamente, sendo inadmissível que um médico o cometa.Trata-se assim de um crime.

- O erro de diagnóstico: o diagnóstico é muitas vezes genérico, pois, na verdade, são desconhecidas as causas de 25 a $30 \%$ das doenças.

*Professor na Escola Superior de Saúde da Universidade de Aveiro.

Médico de Família na Unidade de Saúde Familiar Marquês de Marialva, Cantanhede.
- O erro de procedimento: a actuação (perícia) do médico deve ser ajustada a cada momento, seguindo a evolução clínica (diagnóstica e/ou terapêutica) e de acordo com as respostas do paciente. Tudo deve ser corrigido passo a passo, para que o desvio seja o menor possível e o retorno ao procedimento correcto seja mais fácil, rápido e com as menores sequelas possíveis.

- O erro deliberado, que é realizado para tratar um mal maior.

- O erro profissional: o Direito tende a assim considerar o erro decorrente de falha não imputável ao médico, e que depende das naturais limitações da Medicina que não possibilitam sempre e com certeza o estabelecimento de um diagnóstico exacto. A omissão de dados e/ou informações pelo paciente também contribui para este tipo de erro.

- O erro técnico: refere-se a erro do médico procedente de falhas estruturais, quando os meios (falta de equipamentos) ou as condições de trabalho na instituição por ocasião da consulta médica são insuficientes ou ineficazes para uma resposta satisfatória.

Compete ao médico lidar com o bem mais precioso para a pessoa humana: a vida, com as múltiplas funções de órgãos vitais, com a honra do ser humano e seus valores mais significativos e íntimos, e ainda com o património afectivo da pessoa, incluindo os seus entes mais queridos. Isto somente bastaria para conceder à medicina um incómodo privilégio entre as ciências humanas e criar sobre ela uma extraordinária expectativa. Para a sociedade em geral a medicina tudo pode e a todo momento. A começar pela origem comum entre médico e sacerdote, que leva à presunção de ser o médico o legítimo herdeiro de poderes excepcionais sobre a vida e a morte, uma espécie de representante não autorizado do criador. Tudo isto agravado pela trajectória declinante da religião, abrindo espaço na expectativa da sociedade secular. $\mathrm{O}$ dano decorrente do erro médico é quase sempre de carácter irreparável. Porém, significa nada ou quase nada para a espécie humana, mas 
tudo ou quase tudo para o próprio indivíduo que o sofreu. Isto torna o erro médico grave, sempre grave. $\mathrm{O}$ erro médico é o reverso da expectativa de quem busca a melhoria do próprio corpo, ou seja, é a antítese da cura pretendida. Menos grave seria o médico não curar. $\mathrm{O}$ dano imposto à pessoa humana tem uma importância excepcional. Não se pode minimizar a gravidade social do erro médico, quase sempre em desacordo com o conceito de gravidade médica ou, então, a frustração do paciente em não alcançar o resultado pretendido.

A visão actual do erro médico está impregnada de interesses corporativos, interesses da comunicação social e interesses indemnizatórios inerentes à responsabilidade civil. Os interesses corporativos buscam dissimular o erro médico, descaracterizá-lo ou despersonalizá-lo em detrimento da instituição onde ocorre. Nesse caso a falha humana é subestimada pelo comitente, que busca apenas nos meios de trabalho a justificativa para o erro, que logo se converte «no erro sem culpa». No que concerne ao interesse da comunicação social, a Medicina tem um fascínio especial, pois os seus espectaculares progressos são igualados aos erros clamorosos na capacidade para atrair leitores. Por fim, os interesses lucrativos e indemnizatórios estimulados pela florescente indústria do direito de reparações civis por danos e perdas. Pode-se ainda considerar o comércio dos seguros de risco/responsabilidade profissional.

Os meios de comunicação têm um papel valioso na denúncia dos erros médicos, mas igualmente são poderosos e influentes no sentido de induzir na população uma expectativa de cura em desacordo com o poder resolutivo da ciência médica. Têm o poder de fomentar a imagem da infalibilidade, da cura universal, criando frustrações e desespero na sociedade utente do sistema de saúde. Daí o conceito popular, grosseiro e equivocado de «erro médico» como uma espécie de cura não alcançada. É a visão mística do enfermo decorrente da condição de privado de acesso aos meios de cura (situação mais grave do que a sua enfermidade na maioria das vezes). Parte dessa frustração social com a medicina, do desencanto das pessoas com a salvação pela cura, é desviada para as seitas de salvação espiritual, enquanto outra parte mais esclarecida acaba por resvalar para os sorvedouros da medicina alternativa, moda cultural das classes média e alta.

O médico, de certeza, não comete mais erros do que outros profissionais de nível superior em saúde ou até fora do âmbito da saúde, como no Direito, Arquitectura, Administração, entre outras. A principal diferença está na quase proibição formal de erro face à natureza própria do trabalho médico e do seu objectivo de restabelecer a saúde humana. Embora para o médico a medicina seja um compromisso de meios, para o paciente e para a sociedade ela é vista como uma expectativa de resultados. O paciente vai ao médico em busca de resultados, quase sempre imediatos, e mostra-se ansioso, com a sua vida em jogo e não cede na busca de resultados concretos e positivos, o que torna quase proibitivo o erro médico. Convém lembrar que um resultado adverso em medicina pode ser sinónimo de morte, diferente do resultado adverso do conserto de um aparelho electrodoméstico, ou de outros serviços prestados à sociedade. Ao contrário dos erros cometidos pelo médico que podem gerar resultados adversos a médio ou longo prazo, outros serviços mal executados representam perdas financeiras ou materiais, mas nunca dores, perda de órgãos ou funções ou até de entes queridos.

Esta breve reflexão serve de enquadramento ao dossier deste número da Revista Portuguesa de Clínica Geral, em que José Fragata vai abordar a segurança dos doentes como indicador de qualidade em saúde, ${ }^{3}$ Maria José Ribas os eventos adversos em Cuidados de Saúde Primários e a necessidade de se criar uma Cultura de Segurança, ${ }^{4}$ Ana Maria Sequeira a natureza e frequência dos erros na actividade de Medicina Geral e Familiar, ${ }^{5}$ Ema Paulino explora a opinião e experiências de um grupo de stakeholders relativamente à relação interprofissional entre farmacêuticos comunitários e mé$\operatorname{dicos}^{6} \mathrm{e}$, por fim, Isabel Santos refere-se às estratégias de governação clínica. ${ }^{7}$

\section{REFERÊNCIAS BIBLIOGRÁFICAS}

1. Gomes JC. Erro médico: reflexões. Revista Bioética 1994;2(2). Disponível em: http://revistabioetica.cfm.org.br/index.php/revista_bioetica/article/view/459/342 [acedido 26/11/2010].

2. Fragata J. Risco clínico: complexidade e performance. Coimbra: Almedina; 2006.

3. Fragata J. A segurança dos doentes: indicador de qualidade em saúde. Rev Port Clin Geral 2010 Nov-Dez; 26 (6): 564-70.

4. Ribas MJ. Eventos adversos em cuidados de saúde primários: promover uma cultura de segurança. Rev Port Clin Geral 2010 Nov-Dez; 26 (6): 585-9. 
5. Sequeira AM, Martins L, Pereira VH. Natureza e frequência dos erros na actividade de Medicina Geral e Familiar geral num ACeS - estudo descritivo. Rev Port Clin Geral 2010 Nov-Dez; 26 (6): 572-84.

6. Paulino E, Guerreiro M, Cantrill JA, Martins AP, Costa FA, Benrimoj SI. Community pharmacists' and physicians' inter-professional work: insights from qualitative studies with multiple stakeholders Rev Port Clin Geral 2010 Nov-Dez; 26 (6): 590-606.

7. Santos I, Sá E. Estratégias de governação clínica. Rev Port Clin Geral 2010 Nov-Dez; 26 (6): 607-13.

\section{CONFLITOS DE INTERESSE}

A autor declarou não possuir conflitos de interesses.

\section{ENDEREÇO PARA CORRESPONDÊNCIA}

José Augusto Simões

Escola Superior de Saúde da Universidade de Aveiro

Campus Universitário de Santiago, Edifício III, 3810-193 - Aveiro

jars@ua.pt

Recebido em 02/01/2011

Aceite para publicação em 02/01/2011

\section{NATÁLIA FERREIRA}

Maria Natália Marques Heitor Frazão Ferreira.

Nascida em 1955.

\section{FORMAÇÃO ACADÉMICA}

Licenciada em Medicina pela Faculdade de Ciências Médicas de Lisboa. Especialista em Estomatologia.

\section{FORMAÇÃO ARTÍSTICA}

Curso de Pintura, na Sociedade Nacional de Belas Artes (SNBA), Lisboa,2010-2011. Curso de Pintura, na Sociedade Nacional de Belas Artes (SNBA), Lisboa, 2009-2010

Curso de Pintura, na Sociedade Nacional de Belas Artes (SNBA), Lisboa,2008-2009

Curso de Pintura, na Sociedade Nacional de Belas Artes (SNBA), Lisboa,2007-2008

Atelier de pintura a óleo na Papelaria Fernandes de Outubo de 2005 a Março de 2007

Workshop de pintura da Papelaria Fernandes em 2007. Workshop de pintura da Papelaria Fernandes em 2006.

\section{EXPOSIÇÕES}

Exposição colectiva de pintura, Junta de Freguesia de Santa Isabel, Dezembro 2010

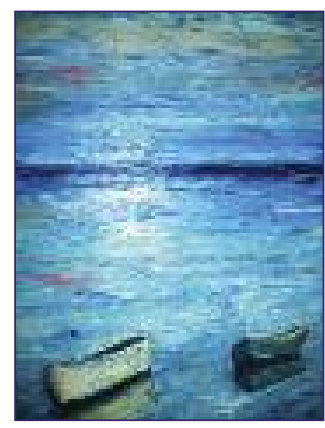

Contemplação Natália Ferreira Acrílico sobre tela

Exposição colectiva de pintura, Junta de Freguesia de S. Sebastião da Pedreira, Novembro 2010

Exposição colectiva de pintura, SNBA, 2010

Exposição colectiva de pintura, Junta de Freguesia de S. Vicente de Fora, 2010

Exposição colectiva de pintura, Junta de Freguesia de Santa Isabel, Junho 2010

Exposição colectiva de pintu-

ra, Junta de Freguesia da Penha de França, 2010 Exposição colectiva de pintura, Junta de Freguesia de S. Sebastião da Pedreira, 2010

Exposição colectiva de pintura, Atelier de Fontenova/HLA, Santiago de Cacém, 2010

Exposição colectiva de pintura, Junta de Freguesia Santos-O-Velho, 2010

Exposição colectiva de pintura, SNBA, 2009

Exposição colectiva de pintura, Junta de Freguesia de S. Vicente de Fora, 2009

Exposição colectiva de pintura, SNBA, 2008

Sócia do Círculo Nacional D`Artes e Poesia 